\title{
A pustule from Portugal
}

\author{
J Dylewski MD ${ }^{1,2}$, Kyle Sheppard ${ }^{2}$
}

A2-year-old woman was admitted to hospital with a sixAday history of fever as high as $40^{\circ} \mathrm{C}$, chills, sweats and headache. She also complained of generalized weakness, sore throat and a nonproductive cough. These symptoms had been evaluated in the emergency room three days previously, at which time a small cutaneous lesion on the upper medial portion of the left breast was noted. She was given a prescription for cefuroxime $500 \mathrm{mg}$ twice daily, which she took, but she did not improve. She returned on the day of admission because of a new nonpruritic rash over her entire body, including the palms of her hands and the soles of her feet.

The patient was a schoolteacher and had no significant past medical history. She had returned from a one-month vacation in Portugal one day before the onset of her symptoms. No family members were ill. She had stayed mainly in the countryside and had gone hiking in wooded areas.

On examination, she appeared to be ill with a temperature of $38.9^{\circ} \mathrm{C}$, a pulse of 145 beats $/ \mathrm{min}$, a blood pressure of $110 / 50 \mathrm{mmHg}$ and a respiratory rate of 18 breaths/min. There was a slight conjunctival injection. The cardiorespiratory examination was normal and no organomegaly or adenopathy was present. Her body was covered with a nonblanching erythematous and ecchymotic maculopapular rash that involved the palms and soles. A small (1 to $2 \mathrm{~mm}$ ) crusted cutaneous ulceration was present on the left breast.

Relevant laboratory data included a hemoglobin level of $118 \mathrm{~g} / \mathrm{L}$, leukocyte count of $6.3 \times 10^{9} / \mathrm{L}$, platelet count of $124 \times 10^{9} / \mathrm{L}$, alkaline phosphatase level of $341 \mathrm{IU} / \mathrm{L}$ (three times the normal level), alanine aminotransferase level of $350 \mathrm{IU} / \mathrm{L}$ (nine times the normal level), aspartate aminotransferase level of $385 \mathrm{IU} / \mathrm{L}$ (nine times the normal level), gamma-glutamyl transpeptidase level of 208 (four times the normal level), and a normal chest radiograph and abdominal ultrasound. She continued to have daily fevers up to $39^{\circ} \mathrm{C}$ and her leukocyte count rose to $16.8 \times 10^{9} / \mathrm{L}$. Serological tests for hepatitis A immunoglobulin M (IgM), hepatitis B surface antigen, rubella IgM and measles IgM were all negative.

What is your diagnosis and what therapy would you initiate?

continued on page 58

${ }^{1}$ Division of Infectious Diseases, St Mary's Hospital, Montreal, Quebec; ${ }^{2}$ Faculty of Medicine, McGill University, Montreal, Quebec

Correspondence: Dr J Dylewski, St Mary's Hospital, 3830 Lacombe Avenue, Montreal, Quebec H3T 1M5.

Telephone 514-345-3511 ext 3075, fax 514-734-2607, e-mail joe.dylewski@ssss.gouv.qc.ca 
continued from page 55

\section{DIAGNOSIS}

On the strong suspicion of a rickettsial disease, the patient was started on gatifloxacin pending results of serological testing. There was some decrease in the rash and general improvement, but the fever persisted for another $48 \mathrm{~h}$ and the patient was then switched to oral doxycycline $100 \mathrm{mg}$ twice daily. Within $24 \mathrm{~h}$ of the switch, she became afebrile and the rash resolved. The patient was discharged from hospital and all laboratory parameters had returned to normal on a follow-up visit one week later. Serological testing for rickettsial disease was performed by Dorothy McColl at the Canadian Science Centre for Human and Animal Health (Winnipeg, Manitoba) and showed an initial titre of less than 1:32, with a convalescent titre of 1:512 to Rickettsia rickettsii. The causative agent of Mediterranean spotted fever is Rickettsia conori and specific testing for this organism is unavailable in Canada. However, there is serological cross-reactivity among members of the spotted fever group. It is our belief that the patient had contracted Mediterranean spotted fever (Boutonneuse fever) in Portugal.

\section{DISCUSSION}

Mediterranean spotted fever is acquired through the bite of the dog tick, Rhipicephalus sanguineus. The incubation period is five to seven days after an often ignored tick bite. Symptoms usually include fever, headache, myalgias, malaise, gastrointestinal disturbance and rash. There is endothelial invasion by the organism, leading to vasculitis and tissue necrosis. This is manifested at the tick bite site by the formation of an eschar, the 'tache noire'. Complications of infection include polyneuropathy (1), renal failure, thrombocytopenia and even death (2). The diagnosis can be made by combining the clinical and epidemiological information and performing rickettsial serological testing on acute and convalescent samples. In some centres, blood and/or skin biopsy specimens have been cultured in cell lines (3) or inoculated into guinea pigs. The treatment of choice is doxycycline but quinolones and the newer macrolides have also been used successfully $(4,5)$.

\section{REFERENCES}

1. Popivanova N, Hristova D, Hadjipetrova E. Guillain-Barré polyneuropathy associated with Mediterranean spotted fever: case report. Clin Infect Dis 1998;27:1549.

2. Yagupsky P. Mortality in serologically unconfirmed Mediterranean spotted fever. J Infect Dis 1999;181:809-12.

3. LaScola B, Raoult D. Diagnosis of Mediterranean spotted fever by cultivation of Rickettsia conori from blood and skin samples using the centrifugation-shell vial technique and by detection of $R$. conori in circulating endothelial cells: a 6-year follow-up. J Clin Microbiol 1996;34:2722-7.

4. Ruiz Beltran R, Herrero JI. Evaluation of ciprofloxacin and doxycycline in the treatment of Mediterranean spotted fever. Eur J Clin Microbiol Infect Dis 1992;11:427-31.

5. Cascio A, Colomba C, Antinori S, Paterson DL, Titone L. Clarithromycin versus azithromycin in the treatment of Mediterranean spotted fever in children: a randomised controlled trial. Clin Infect Dis 2002;34:154-8. 


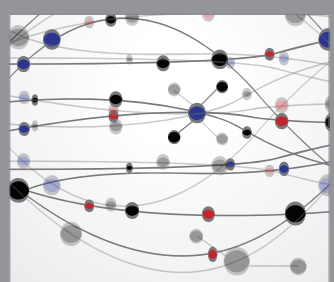

The Scientific World Journal
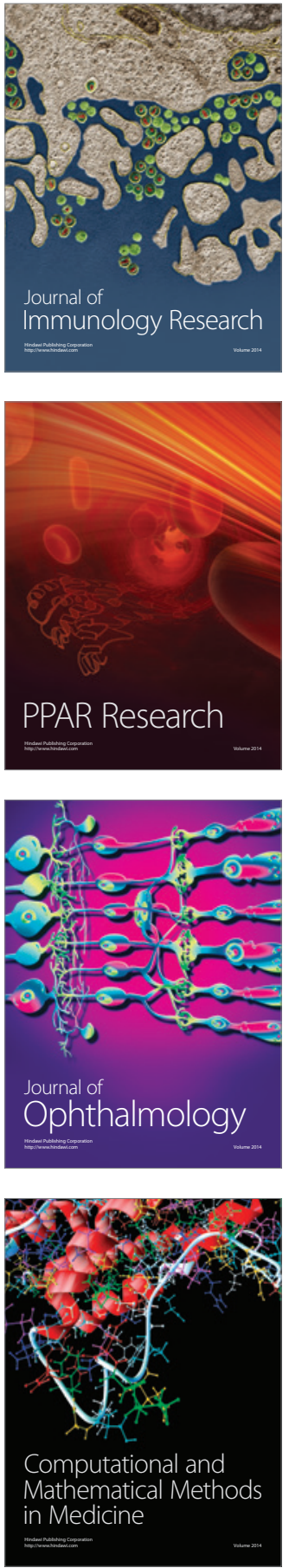

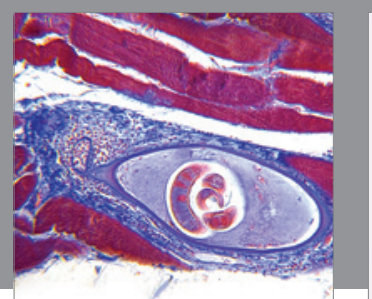

Gastroenterology Research and Practice

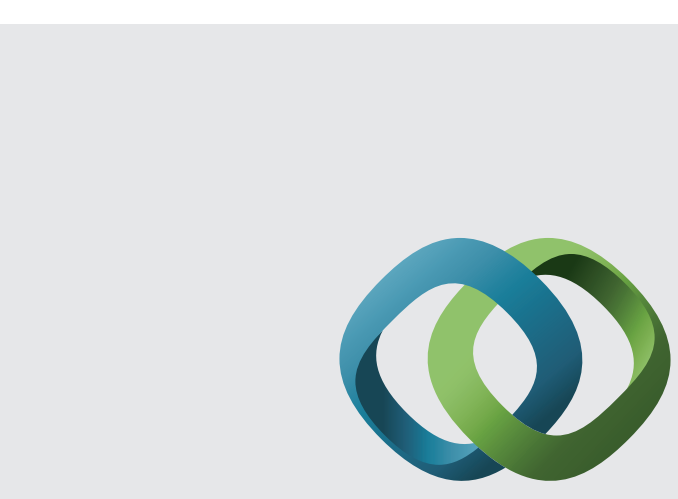

\section{Hindawi}

Submit your manuscripts at

http://www.hindawi.com
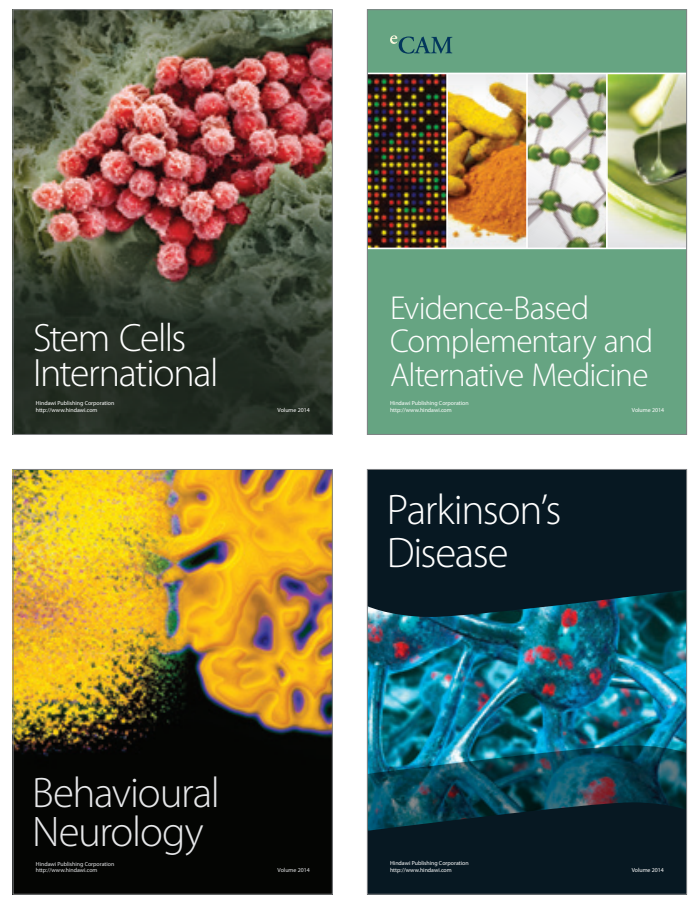
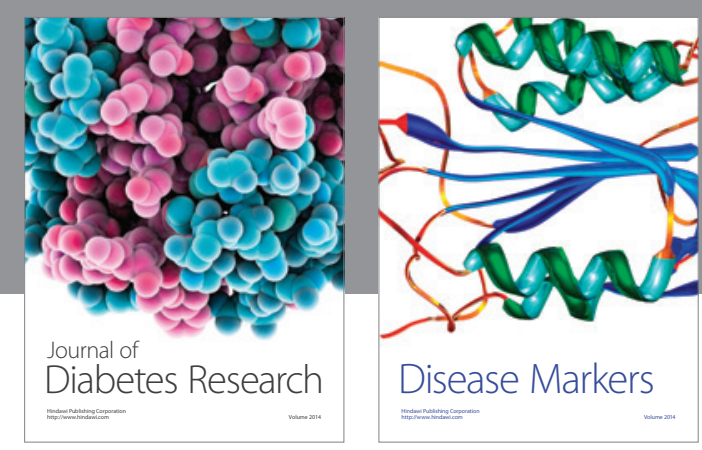

Disease Markers
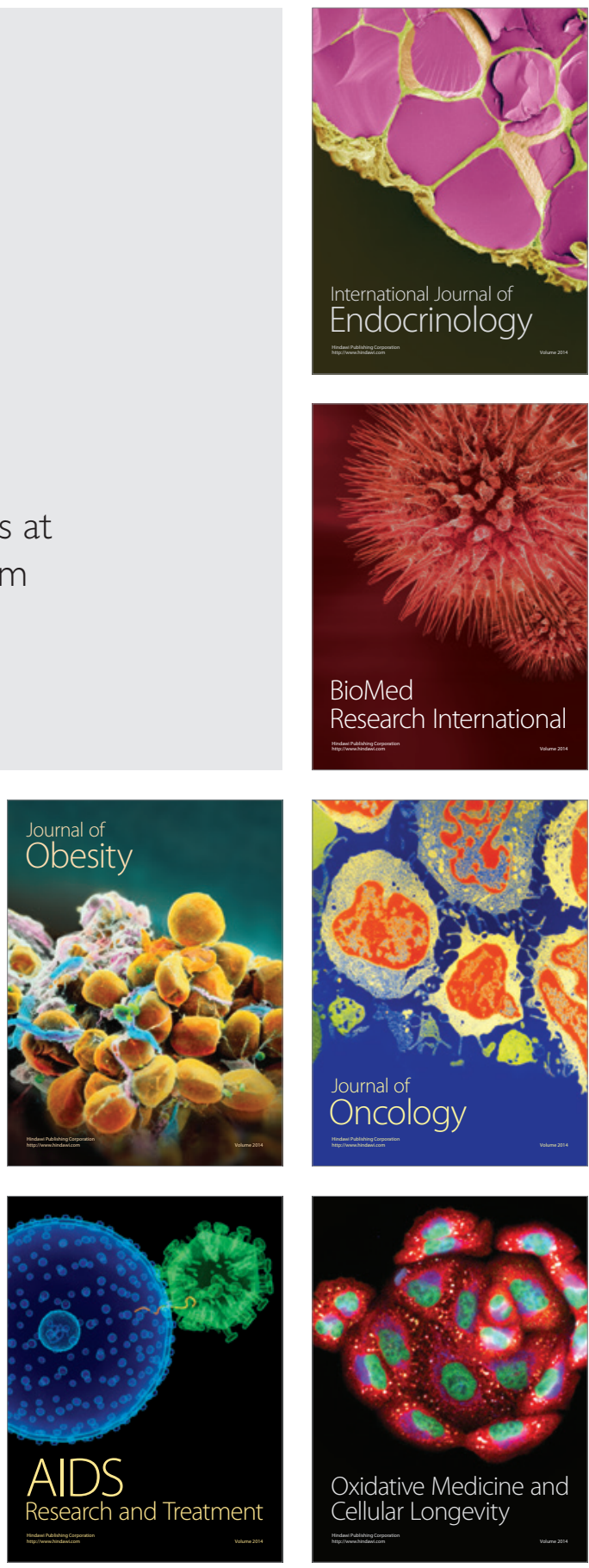